\title{
Implications of antibiotherapy in Clostridium Difficile infection to hospitalized patients in Dolj county (Romania)
}

\author{
Livia Dragonu'1,2, Augustin Cupsa ${ }^{1,2}$, Irina Niculescu' ${ }^{1,2}$, Lucian Giubelan ${ }^{1,2}$, \\ Florentina Dumitrescu ${ }^{1,2}$, Andreea Cristina Stoian ${ }^{1}$, Iulian Gheorghe Diaconescu ${ }^{1,2}$ \\ ${ }^{1}$ University of Medicine and Pharmacy, Craiova, Romania \\ ${ }^{2}$ Clinic Hospital for Infectious Diseases and Pneumology "Victor Babes", Craiova, Romania
}

\begin{abstract}
Objectives. The paper presents the role of the antibiotic treatment and of the favoring factors independent on the antibiotherapy, identified in the occurrence of Clostridium difficile infection (CDI) in hospitalized cases in Dolj County.

Material and method. Two groups of patients were analyzed: the CDI AB group (178 cases of CDI that received antibiotic treatment) and the $C D I$ non $A B$ group (36 CDI cases which did not receive antibiotic treatment) recorded between July 2014 and December 2016).

Results. The antibiotherapy was a significant risk factor, registered at $83.2 \%$ of the cases. The classes of antibiotics associated with the onset of CDI were cephalosporins ( $73.5 \%$ of cases), quinolones $(24.2 \%)$, penicillins $(13.4 \%)$, tuberculostatics $(6.1 \%)$, carbapenems $(5.6 \%)$. The cases came from the general surgery sections $(25.2 \%)$, pneumophtiziology $(16.8 \%)$, intensive care $(13.5 \%)$, neurology $(12.1 \%)$, nephrology $(6.1 \%)$, orthopedics $(6.1 \%)$, cardiology $(4.2 \%)$, plastic surgery $(4.2 \%)$, urology $(3.7 \%)$.

$\mathrm{CDI}$ non $\mathrm{AB}$ recorded a higher percentage compared to $\mathrm{CDI} A \mathrm{~B}$ in the Intensive care sections $(30.6 \%$ versus $10.1 \%)$. The comparative analysis of the characteristics of the patients with CDI AB and CDI non AB did not reveal significant differences linked to the age, sex, interval between admission and onset of the symptoms, recent gastrointestinal surgery or taking antacids.

Conclusions. The antibiotherapy is an important risk factor for CDI, cephalosporins and quinolones being frequently-involved. Being admitted to the intensive care unit and the severity of the underlying conditions had a significant role in the appearance of $\mathrm{CDI}$ in patients without exposure to antibiotics.
\end{abstract}

Keywords: Clostridium difficile; risk factors; antibiotics

\begin{abstract}
ABBREVIATIONS
CDI: Clostridium difficile infection;

CDI AB: Clostridium difficile infection after administration of antibiotics;

CDI non AB: Clostridium difficile infection without administration of antibiotics;

RR: Relative risk ; 95\% CI: 95\% confidence interval

ASA: American Society of Anesthesiology
\end{abstract}

\section{INTRODUCTION}

The Clostridium difficile infection (CDI) has become a common cause of nosocomial diarrhea, being correlated with hospitalization, antibiotic therapy, over 65 years of age, and associated comor- bidities. The antibiotic treatment causes disruption of indigenous intestinal microflora, allowing C. difficile to multiply and produce the toxin responsible for clinical manifestations of the disease (1). Recent observations suggest that the antimicrobial re- 
sistance of strains of $C$. difficile plays an increasing important role in CDI epidemiology (2). C. difficile clindamycin resistant strains develop in an environment where the comensal flora has been suppressed by the administration of clindamycin, being associated with the occurrence of large CDI outbreaks (3). The same concept can be applied to cephalosporins and fluoroquinolones when administered to a patient who is exposed to $C$. difficile strains resistant to these antibiotics. The occurrence of fluoroquinolone resistant epidemiological strains (type $\mathrm{BI} / \mathrm{NAP} 1 / 027)$ is associated with the frequent use of these antibiotics (4).

Patients receiving antimicrobial agents and exposed to $C$. difficile do not develop the disease equally. This is attributed to variables in the complex pathogenesis of this disease, which include the ability of the immune system to produce a response to antitoxic antibodies to $C$. difficile (1). The patients who do not develop raised titres in the IgG anti-toxin serum after the first episode of CDI appear to be more recurrent than patients who had an adequate immune response (5). This is one of the reasons why the older people or with certain comorbidities are more susceptible to CDI.

In this context, the work follows the link between CDI and the antibiotic treatment in hospitalized cases by:

- assessing the role of the antibiotic treatment as a risk factor in the development of CDI;

- the correlation with the type of antibiotics administration;

- identifying the factors favoring the development of CDI in cases without antibiotic therapy.

\section{MATERIAL AND METHOD}

There were retrospectively analyzed (July 2014 - December 2016) the records of 214 cases of hospital onset CDIs reported by hospitals in the county of Dolj (România). Cases of over 18 years of age in whom digestive symptoms occurred during hospitalization (48 hours after admission) were included, the laboratory diagnosis being confirmed by identifying $C$. difficile toxins in the stool.

From the study records we have retained the following data: antibiotic administration (antibiotic name), demographic data (age, sex, home environ- ment), the patient's ward, the time interval of the symptoms onset after admission, favoring factors for CDI (antacid medication, recent gastrointestinal surgery, immunodepression), the evolution of cases. The cases were divided according to the antibiotic administration during the admission in two comparative lots:

- Lot 1 (178 cases) CDI patients receiving antibiotic during hospitalization (CDI AB);

- Lot 2 (36 cases) of CDI patients in whom the disease occurred without being associated with antibiotic therapy (CDI non AB).

The comparative analysis of the two batches used median determination, relative risk (RR) with 95\% confidentiality interval $(\mathrm{CI})$ and Chi square test (assuming statistically significant $\mathrm{P}<0.05$ ).

\section{RESULTS}

TABLE 1. Evolution of CDI cases related to antibiotic administration

\begin{tabular}{|l|c|c|c|c|c|}
\hline \multirow{2}{*}{ Time interval } & \multicolumn{4}{|c|}{ CDI whith hospital onset } \\
\cline { 2 - 6 } & \multicolumn{2}{|c|}{ CDI AB } & CDI nonAB & Total \\
\cline { 2 - 6 } & $\begin{array}{c}\text { Nr. } \\
\text { cases }\end{array}$ & $\begin{array}{c}\text { \% of } \\
\text { total }\end{array}$ & $\begin{array}{c}\text { Nr. } \\
\text { cases }\end{array}$ & $\begin{array}{c}\text { \% of } \\
\text { total }\end{array}$ & $\begin{array}{c}\text { Nr. } \\
\text { cases }\end{array}$ \\
\hline July - December 2014 & 13 & 92.8 & 1 & 7.2 & 14 \\
\hline January - December 2015 & 50 & 87.7 & 7 & 12.3 & 57 \\
\hline January - December 2016 & 115 & 80.4 & 28 & 19.6 & 143 \\
\hline Total & 178 & 83.2 & 36 & 16.8 & 214 \\
\hline
\end{tabular}

According to the Table 1 , at $83.2 \%$ of all cases of CDI with hospital-onset they were treated with antibiotic therapy, this being a significant risk factor for CDI onset (RR $=4.9,95 \%$ CI 3.64 to $6.70, p$ $<0.0001)$. The number of CDI cases showed a steady increase over the studied period, being 2.5 times higher in 2016 compared to 2015 (143 cases versus 57 cases).

The annual percentage of patients with CDI who received antibiotic-treatment was $92.8 \%$ (July-December 2014), 87.7\% (2015) and 80.4\% (2016). The increase of the number of CDI cases on the studied period was not correlated with the increase of the annual percentage of cases which received antibiotic treatment $(\mathrm{RR}=1.09,95 \% \mathrm{CI} 0.96$ to 1.23 , $p=0.17$ for 2015 versus 2016).

\section{The antibiotic treatment administered before the CDI debut}

The most frequently used antibiotic classes were, according to Table 2: cephalosporins $(73.5 \%$ 
TABLE 2. Antibiotic class administrated to the cases of $C D I A B(n=178)$

\begin{tabular}{|c|c|c|c|c|c|}
\hline \multicolumn{3}{|c|}{ Antibiotic administered prior to $\mathrm{CDI}$} & \multirow{2}{*}{$\begin{array}{c}\begin{array}{c}\text { Nr. } \\
\text { cases }\end{array} \\
79\end{array}$} & \multirow{2}{*}{$\begin{array}{c}\begin{array}{c}\% \text { of } \\
\text { total }\end{array} \\
44.3\end{array}$} & $\%$ of \\
\hline \multirow{13}{*}{$\begin{array}{l}\text { An bio c } \\
\text { class }\end{array}$} & \multirow{3}{*}{ Cephalosporins } & Ce riaxone & & & \multirow{3}{*}{73.5} \\
\hline & & Cefoperazone & 46 & 25.8 & \\
\hline & & Other cephalosporins & 6 & 3.4 & \\
\hline & \multirow{3}{*}{ Quinolones } & Ciprofloxacin & 24 & 13.5 & \multirow{3}{*}{24.2} \\
\hline & & Moxifloxacin & 10 & 5.6 & \\
\hline & & Levofloxacin & 9 & 5.1 & \\
\hline & \multirow{2}{*}{ Carbapenems } & Imipenem cilasta $n$ & 6 & 3.3 & \multirow{2}{*}{6.1} \\
\hline & & Meropenem & 5 & 2.8 & \\
\hline & \multirow{3}{*}{ Penicillins } & Ampicillin +BLI* & 11 & 6.2 & \multirow{3}{*}{13.4} \\
\hline & & Penicillin & 10 & 5.6 & \\
\hline & & Amoxicillin & 3 & 1.6 & \\
\hline & \multicolumn{2}{|l|}{ Tuberculosta cS } & 11 & 6.1 & 6.1 \\
\hline & \multicolumn{2}{|l|}{ Other an bio cs } & 8 & 4.5 & 4.5 \\
\hline
\end{tabular}

* Beta-lactamase inhibitor

of cases), quinolones $(24.2 \%)$, penicillins $(13.4 \%)$, carbapenems $(5.6 \%)$, tuberculostatics $(6.1 \%)$. The data analysis on administered antibiotics (with or without association) showed that Ceftriaxone (44.3\%), Cefoperazone (25.8\%) and Ciprofloxacin $(13.5 \%)$ were the most common recorded in CDI onset.

\section{Distribution of cases by the profile of the reporting sections}

Depending on the profile of the reporting sections (Table 3), the highest percentage of cases originated of general surgery $(25.2 \%)$ followed by pneumophthisiology (16.8\%), intensive care (13.5\%), neurology (12.1\%), nephrology (6.1\%), orthopedics $(6.1 \%)$, cardiology $(4.2 \%)$, plastic surgery $(4.2 \%)$, urology $(3.7 \%)$.

TABLE 3. Distribution of $C D I A B$ and $C D I$ non $A B$ function of reporting sections

\begin{tabular}{|l|c|c|c|c|}
\hline Reporting section & $\begin{array}{c}\text { CDI AB } \\
\text { Nr. cases } \\
(\%)\end{array}$ & $\begin{array}{c}\text { CDI non AB } \\
\text { Nr. cases } \\
(\%)\end{array}$ & $\mathbf{p}$ & $\begin{array}{c}\text { Total } \\
\text { Nr. cases } \\
(\%)\end{array}$ \\
\hline Pneumoph ziology & $35(19.6)$ & $1(2.7)$ & 0.04 & $36(16.8)$ \\
\hline Neurology & $24(13.4)$ & $2(5.5)$ & 0.21 & $26(12.1)$ \\
\hline Nephrology & $10(5.6)$ & $3(8.3)$ & 0.5 & $13(6.1)$ \\
\hline Cardiology & $7(3.9)$ & $2(5.5)$ & 0.6 & $9(4.2)$ \\
\hline General surgery & $42(23.5)$ & $12(33.3)$ & 0.1 & $54(25.2)$ \\
\hline Orthopedics & $13(7.3)$ & & 0.22 & $13(6.1)$ \\
\hline Plas c surgery & $8(4.5)$ & $1(2.7)$ & 0.6 & $9(4.2)$ \\
\hline Urology & $8(4.5)$ & - & 0.38 & $8(3.7)$ \\
\hline Intensive care & $18(10.1)$ & $11(30.6)$ & 0.001 & $29(13.5)$ \\
\hline Other sec on & $13(7.3)$ & $4(11.1)$ & 0.43 & $17(7.9)$ \\
\hline Total & $178(100)$ & $36(100)$ & 0.0001 & $214(100)$ \\
\hline
\end{tabular}

The antibiotic administration was a significant risk factor for the development of $\mathrm{CDI} A \mathrm{AB}$ in sections of $(\mathrm{RR}=7.0795 \% \mathrm{CI} 3.32$ to $27.1, \mathrm{p}=0.04)$. In $\mathrm{CDI}$ non $\mathrm{AB}$ the main risk factor, independent of the antibiotic, was the severity of the conditions of patient, who required hospitalization in intensive care units.

\section{$C D I A B$ and $C D I$ non $A B$ associated favoring factors}

$\mathrm{CDI} A B$ and $\mathrm{CDI}$ non $\mathrm{AB}$ had affected a higher percentage of patients over 65 years (Table 4). CDI non $\mathrm{AB}$ has reported a higher number of cases in female sex compared to male (61.1\% versus $48.8 \%)$ but with no statistically significant difference. In $\mathrm{CDI}$ non $\mathrm{AB}$ compared to $\mathrm{CDI} \mathrm{AB}$, the percentage of cases from rural areas was higher $(66.6 \%$ versus $49.4 \%$ ) with statistically significant difference ( $\mathrm{p}=$ 0.03 ). The time interval between admission and the onset of symptoms was not shorter in CDI AB compared to non $\mathrm{AB}$ CDI (median 13.7 days versus 13.2 days. The digestive surgery performed 14 days before CDI onset (15.1\% versus $13.8 \%$ ) and antacid administration ( $68.5 \%$ versus $63.8 \%$ ) were not statistically associated significantly with the non AB CDI onset. The neoplastic disease has been a significant factor in the development of CDI non AB (Table 4). 
TABLE 4. Characteristics of the patients with $C D I A B$ compared to $C D I$ non $A B$

\begin{tabular}{|c|c|c|c|}
\hline Characteristics & $\begin{array}{c}\text { CDI AB } \\
(N=178)\end{array}$ & $\begin{array}{c}\text { CDI non } A B \\
(N=36)\end{array}$ & $\mathbf{p}$ \\
\hline Age >60 years $(N(\%))$ & $128(71.9)$ & $27(75)$ & 0.69 \\
\hline Median age (years) & 65.04 & 65.6 & \\
\hline Female (N (\%)) & $87(48.8)$ & $22(61.1)$ & 0.14 \\
\hline Rural environment (N (\%)) & $88(49.4)$ & $24(66.6)$ & 0.03 \\
\hline $\begin{array}{l}\text { Onset under } 14 \text { days of } \\
\text { admission ( } \mathrm{N}(\%))\end{array}$ & $123(69.1)$ & $28(77.7)$ & 0.24 \\
\hline Median admission-onset (days) & 13.7 & 13.2 & \\
\hline Diges ve surgery $(\mathrm{N}(\%))^{*}$ & $27(15.1)$ & $5(13.8)$ & 0.84 \\
\hline Antacid administra on (N (\%)) & $122(68.5)$ & $23(63.8)$ & 0.60 \\
\hline Neoplas c diseases (N (\%)) & $27(15.1)$ & $11(30.5)$ & 0.02 \\
\hline Lethality (N (\%)) & $21(11.8)$ & $8(22.2)$ & 0.08 \\
\hline
\end{tabular}

* Digestive surgery 14 days before CDI

The deaths through $\mathrm{CDI} A \mathrm{AB}$ were recorded in 21 cases $(11.8 \%)$ and by CDI non AB in 8 cases (22, $2 \%$ ) without presenting statistically significant difference $(p=0.08)$ in terms of evolution of the cases (Table 4).

\section{DISCUSSIONS}

Antibiotic therapy was a significant risk factor, recorded in $83.2 \%$ of the cases with CDI with hospital onset tracked in our study. Predrag S. (6) says the treatment with antibiotic can be considered a trigger factor for $70-90 \%$ of CDI cases recorded.

The exposure to antibiotic favors the colonization with $C$. difficile (7), Aronsson B. et al. (8) identifying toxigenic strains at $35 \%$ of the patients treated with antibiotics and $7 \%$ of the patients not treated with antibiotics.

When speaking about the main classes of antibiotics associated to CDI onset a 2015 report identified that similar to our results, the antibiotic treatment favouring CDI in România has been dominated by generic cephalosporins III $(51.2 \%)$ and fluoroquinolones (32.3\%) (9).

Antibiotics identified more frequently in CDI appearance showed differences between different studies (10-12) in the medical literature being initially mentioned clindamycin, penicillins and cephalosporins. A retrospective study by Bignardi G. (13) showed that $2 / 3$ of the patients diagnosed with CDI received cephalosporins, generation 2 and 3 presenting a higher risk of CDI. The fluoroquinolones registered an increase in morbidity and mortality caused by the spread of fluroquinolone-resistant strains of $C$. difficile (BI/ NAP1) after Loo et al. (14) the relative risk associated with the administration of these antibiotics being between 2 and 12.7 .

The antituberculous agents have rarely been associated with CDI. Isoniazid or pyrazinamide has a reduced effect on the intestinal flora, but emergence of $C$. difficile strains, rifampicin-resistant was reported by Obuch in Poland (15) .

Of the total number of CDI studied cases, $16.8 \%$ did not receive antibiotics, the appearance of CDI non $\mathrm{AB}$ questioning the intervention of some independent risk factors for antibiotics that cause a higher susceptibility $C$. difficile for certain people. In the medical sections (Table 3) CDI a has been associated more frequently with chronic pulmonary diseases, neurological, renal and cardiac diseases, antibiotic administration being a significant risk factor for the patients in the sections of pneumophtiziology. Depending on the surgical pathology of the patients, the most cases were recorded in general surgical wards, in orthopedics, plastic surgery and urology without significant differences in CDI appearance depending on the antibiotic therapy. CDI non $\mathrm{AB}$ recorded a statistically significant increase compared to $\mathrm{CDI} A \mathrm{AB}$ in the intensive care units $(30.6 \%$ versus $10.1 \%)$.

The study made by Sung Mi Cho (16) related to the risk factors associated with CDI in Korea has identified that patients with chronic respiratory diseases have an increased risk for CDI both due to the decreasing immunity of the host and to the high rate of infections requiring antibiotic treatment. Kurd et al. (17) suggests that patients with altered physical status (reported to ASA score) or those who receive more than one antibiotic after surgery are at an increased risk of CDI. Postoperatively patients may be more immunosuppressed than the typical patients and more exposed to virulent hospital strains (16). The admission on an intensive care unit is a risk factor for the colonization with $C$. Difficile (18), the severe illnesses being independent risk factors that can cause changes in intestinal flora with CDI development in hospitalized patients (19).

The comparative analysis of the characteristics of patients with $\mathrm{CDI} A B$ and non-AB CDI in our study, in the same way as the results obtained by Brown et al. (18) did not reveal significant differ- 
ences in age, sex, interval between admission and symptoms onset, recent digestive surgery, or administration of antacid medication.

The neoplastic diseases presented a higher risk for $\mathrm{CDI}$ non $\mathrm{AB}$, these patients often being exposed to infections that require antibiotics. According to Predrag S. (6) there are studies that indicate the fact that the oncologic diseases and the associated therapy to these present a higher significant risk for CDI which do not depend on the administration of antibiotics. In our study lethality by CDI did not present significant differences linked to antibiotherapy administration, the higher percentage of the patients with an evolution to lethality in the $\mathrm{CDI}$ non $\mathrm{AB}$ group $(22.2 \%$ versus $11.8 \%)$ being associated with the aggravation of the subjacent pathology of the patients.

\section{CONCLUSIONS}

1. The antibiotic therapy was an important risk factor, significantly associated with the develop- ment of CDI in patients with chronic respiratory diseases.

2. Most of the antibiotic classes have determined CDI, a higher risk being registered by the use of cephalosporins and quinolones.

3. In the CDI appearance to patients without exposure to antibiotic a significant role played the admission in the intensive care units and the severity of the underlying conditions.

The CDI epidemiology continues to present changes, the frequent association with the medical care and with the antibiotic use, requiring an increased level of attention to the judicious use of the antibiotics and to the transmission of the infection inside the hospital environment.

Conflict of interest: none declared Financial support: none declared

\section{$\overline{\text { REFERENCES }}$}

1. Poutanen S.M., Simor A.E. Clostridium difficile - associated diarrhea in adults. CMAJ. 2004; 171:51-8.

2. Gerding D.N. Clindamycin, cephalosporins, fluoroquinolones, and Clostridium difficile - associated diarrhea: this is an antimicrobial resistance problem. Clin Infect Dis. 2004; 38:646-8.

3. Climo M.W., Israel D.S., Wong E.S., W. et al. Hospital-wide restriction of clindamycin: effect on the incidence of Clostridium difficile - associated diarrhea and cost. Ann Intern Med. 1998; 128(12 pt 1):989-95.

4. McDonald L.C., Killgore G.E., Thompson A. et al. An epidemic, toxin gene-variant strain of Clostridium difficile. N Engl J Med. 2005; 353: 2433-41.

5. Kyne L., Warny M., Qamar A., Kelly C.P. Association between antibody response to toxin $A$ and protection against recurrent Clostridium difficile diarrhoea. Lancet. 2001; 357:189-93.

6. Predrag S. Analysis of risk factors and clinical manifestations associated with Clostridium difficile disease in Serbian hospitalized patients. Braz J Microbiol. 2016; 47 (4):902-10.

7. Riggs M.M., Sethi A.K., Zabarsky T.F. et al. Asymptomatic carriers are a potential source for transmission of epidemic and nonepidemic Clostridium difficile strains among long-term care facility residents. Clin Infect Dis. 2007; 45: 992-998

8. Aronsson B., Möllby R., Nord C.E. Antimicrobial agents and Clostridium difficile in acute enteric disease: epidemiological data from Sweden, 1980-82. J Infect Dis. 1985; 151:476-81

9. Centrul Naţional de Supraveghere şi Control al Bolilor Transmisibile. Analiza date supraveghere; accesat la adresa (http://www.cnscbt.ro/ index.php/analiza-date-supraveghere/409-in-in-romania-nov-2015/ file)

10. Muto C.A., Pokrywka M., Shutt K. et al. A large outbreak of Clostridium difficile - associated disease with an unexpected proportion of deaths and colectomies at a teaching hospital following

increased fluoroquinolone use. Infect Control Hosp Epidemiol. 2005; 26:273-80.

11. Pepin J., Saheb N., Coulombe M.A. et al. Emergence of fluoroquinolones as the predominant risk factor for Clostridium difficile associated diarrhea: a cohort study during an epidemic in Quebec. Clin Infect Dis. 2005; 41:1254-60.

12. Kazakova S.V., Ware K., Baughman B. et al. A hospital outbreak of diarrhea due to an emerging epidemic strain of Clostridium difficile. Arch Intern Med. 2006; 166:2518-24.

13. Bignardi G.E. Risk factors for Clostridium difficile infection. $J$ Hosp Infect. 1998; 40:1-15.

14. Loo V.G., Poirier L., Miller M.A. et al. A predominantly clonal multiinstitutional outbreak of Clostridium difficile - associated diarrhea with high morbidity and mortality. N Engl J Med. 2005; 353:2442-9.

15. Obuch-Woszczatynski P., Dubiel G., Harmanus C. et al. Emergence of Clostridium difficile infection in tuberculosis patients due to a highly rifampicin-resistant PCR ribotype 046 clone in Poland. Eur J Clin Microbiol Infect Dis. 2013; 32 (8): 1027-1030

16. Sung Min Cho, Jae Joon Lee, Hee Jung Yoon. Clinical risk factors for Clostridium difficile - associated diseases. Braz J Infect Dis. 2012; 16 (3):256-61

17. Kurd M.F., Pulido L., Joshi A. et al. Clostridium difficile infection after total joint arthroplasty: who is at risk? J Arthroplasty. 2008; 23:839-842.

18. Brown E., Talbot G.H., Axelrod P. et al. Risk factors for Clostridium difficile toxin-associated diarrhea. Infect Control Hosp Epidemiol. 1990; 11: 283-290

19. Al-Eidan F.A., McElnay J.C., Scott M.G., Kearney M.P. Clostridium difficile -associated diarrhoea in hospitalised patients. J Clin Pharm Ther. 2000; 25(2):101-9 